\title{
Contraception among girls who have had more than one partner by age 16 years: method use and pregnancy risk-taking behaviour
}

Lisa M McDaid, Helen Sweeting, Katie Buston

\begin{abstract}
Background Attempts to address the 'problem' of teenage pregnancy need to further explore contraceptive use among young people at potentially greatest risk. We examine contraceptive use among a particularly vulnerable subgroup: girls who reported having had sex with more than one partner by age 16 years.
\end{abstract}

Methods Females ( $n=435)$ completed questionnaires as part of the Scottish SHARE school-based sex education trial, reporting on contraceptive use at three episodes of sexual intercourse: first, first with most recent partner, and most recent.

Results Most used some form of contraception at each episode but a quarter reported withdrawal, putting on a condom before ejaculation or non-use. Some $57 \%$ of the girls reported using methods that suggested lower levels of pregnancy risk-taking behaviour at all three episodes, but $20 \%$ reported method use suggestive of greater risktaking behaviour at one episode, $12 \%$ at two, and $11 \%$ at all three. In multivariate analysis, the factors associated with greater pregnancy risk-taking behaviour were living in social or rented accommodation, not knowing where to get prescription contraceptives, having pressurised or unexpected or spur of the moment sex, and not having talked to their partner about protection prior to sex.

Conclusions Most girls used an effective method of contraception at each episode of intercourse but a sizeable minority reported use of no contraception, or an ineffective method, which suggested greater pregnancy risk-taking behaviour; one in ten at all three episodes. Particular efforts are required to further understand and better target those girls who are putting themselves at repeated risk of pregnancy.

Keywords adolescent girls, contraception, pregnancy, risk-taking behaviour

J Fam Plann Reprod Health Care 2010; 36(3): 141-146

(Accepted 8 April 2010)

\section{Introduction}

The UK has one of the highest teenage pregnancy rates in the developed world. ${ }^{1}$ In Scotland in 2006, it was 57.9 per 1000 females aged 15-19 years and 8.1 per 1000 aged 13-15 years, having remained fairly consistent over the previous decade. ${ }^{2}$ In England, the 2007 rates were 41.7 per 1000 females aged $15-17$ years and 8.3 per 1000 aged 13-15 years. ${ }^{3}$ Most adolescents in the UK report using contraception at first sexual intercourse. Only $10 \%$ of female 16-19-year-olds in a national survey conducted in 2000 reported using no method, but this increased with declining age at first intercourse and early sexual debut was associated with pregnancy experience by age 18.4

If governmental attempts to address the 'problem' of teenage pregnancy are to succeed, 5,6 we need to understand more about those young people who fail to use contraception, or who use methods traditionally thought to be less effective at preventing pregnancy, and likely to be defined as high-risk in formal sex education. In this article we examine contraceptive use among girls who reported having had sex with more than one partner by age 16 years. A focus on those whose sexual debut was relatively early and who had two or more partners enables us to learn more about what could be a particularly vulnerable subgroup. Although a minority (435 girls, 14\%, from an overall sample of $3116^{7}$ ), examining their contraceptive use could contribute to the understanding and prevention of unwanted sexual outcomes. We examine contraceptive use across three episodes of sexual intercourse. Specifically, we:

MRC Social and Public Health Sciences Unit, Glasgow, UK Lisa M McDaid (nee Williamson), PhD, Senior Investigator Scientist Helen Sweeting, PhD, Senior Investigator Scientist

Katie Buston, PhD, Senior Investigator Scientist

Correspondence to: Dr Lisa McDaid, MRC Social and Public Health Sciences Unit, 4 Lilybank Gardens, Glasgow G12 8RZ, UK. E-mail: lisa@sphsu.mrc.ac.uk

\section{Key message points}

- This study of girls with more than one sexual partner by age 16 years found most used an effective contraceptive method at sexual intercourse.

- A sizeable minority reported using methods suggestive of greater pregnancy risk-taking behaviour (i.e. withdrawal, condom just before ejaculation, or non-use) at some point; one in ten consistently did so.

- Particular efforts are required to further understand and better target those girls who are putting themselves at repeated risk of pregnancy.

- Describe contraceptive method use at first, first with most recent partner, and most recent sexual intercourse;

- Examine pregnancy risk-taking behaviour across the three episodes; and

- Report on the association between greater pregnancy risk-taking behaviour and a range of demographic, accessibility and experiential factors.

The article concludes by discussing the importance of gaining a deeper understanding of pregnancy risk-taking behaviour among this subgroup of girls.

\section{Methods \\ SHARE sample}

Data were collected between 1996 and 2000 as part of the randomised trial of a school-based sex education (SHARE) intervention in Scotland. ${ }^{7}$ Opt-out consent was obtained from pupils and parents. Two cohorts of male and female pupils, from consecutive years in 25 secondary schools, were surveyed at age 13/14 years $(n=7616 ; 3794$ females, mean age 14.2 years) and at $15 / 16$ years $(n=5854 ; 3116$ females, mean age 16.1 years), with an overall participation rate of $70 \%$ of the original issued sample at age 15/16 years. Comparison with data from the 1991 census showed the baseline sample to be representative of Scottish 14-year-olds in terms of socioeconomic status and family 
structure. ${ }^{7}$ Self-completion questionnaires were administered by researchers in classrooms under examination conditions, in the absence of teachers. At $15 / 16$ years, questionnaires were also mailed to school leavers for return in prepaid envelopes.

The results of the trial have been published. ${ }^{7,8}$ Since the intervention did not improve contraceptive use, ${ }^{7}$ analyses are based on the full sample.

\section{Sample inclusion and data considerations Sexual experience}

Of the 3116 girls surveyed at age $15 / 16$ years, 1175 (38\%) reported (hetero)sexual experience. The questionnaire only collected data on three particular episodes of heterosexual intercourse: first ever, first with most recent (if more than one) partner, and most recent. Respondents were routed through the questionnaire so that only those with more than one experience of sex or more than one partner answered the relevant questions, and our analyses are limited to respondents for whom each event (first, first with most recent partner, and most recent sexual intercourse) was a distinct, individual episode of sexual intercourse $(n=435)$. This enabled us to concentrate on the subgroup who reported a relatively early sexual debut (66\% reported first sex by age 14 years) and had more than one partner $(59.0 \%$ had three or more sexual partners, compared with $12.5 \%$ of the remaining sexually active females; $p<0.001$ ), and to examine contraceptive use and pregnancy risk-taking behaviour across the three distinct episodes of intercourse.

\section{Contraceptive use and pregnancy risk-taking behaviour measures}

Respondents were asked to indicate methods of contraception used at each episode, from a list of eight options: none, withdrawal, condom put on just before ejaculation, condom used throughout (the questionnaire did not distinguish between male and female condoms), contraceptive pill, emergency contraception (EC), other, or don't know (latter two excluded from analyses because of small numbers). The contraceptive implant and injection were not listed; the latter was only reported by a small number of respondents who wrote it in the 'other' category. The most medically effective method (for pregnancy prevention) was coded when more than one was indicated (e.g. respondents selecting withdrawal and the pill were coded as pill users). However, combined use of the pill and condom was considered as a category in itself because this could represent a particular choice of dual protection from pregnancy and sexually transmitted infections.

Different contraceptive methods offer different levels of pregnancy protection. ${ }^{9}$ When used correctly, the pill, injection, condoms, or a combination of these offer greater, albeit varying, levels of pregnancy protection than withdrawal or putting on a condom before ejaculation (although there is debate about the efficacy of the latter methods in the scientific literature $\left.{ }^{10,11}\right) .{ }^{9}$ Numbers were insufficient to assess methods individually so the pill, injection, condoms, or a combination of these three (all traditionally advocated for pregnancy prevention in formal school or service provider sex education) were categorised as suggesting the girls in this group displayed lower levels of pregnancy risk-taking behaviour. EC use was also included in this category. Qualitative research, including our own, has shown that EC is predominantly viewed by young women as a 'back-up' method. ${ }^{12-14}$ Use, therefore, even if resulting from contraceptive non-use or failure, suggests they consider themselves at risk of pregnancy and address this, albeit postcoitally. Conversely, withdrawal, putting a condom on just before ejaculation, and non-use of contraception were categorised as suggestive of greater pregnancy risk-taking behaviour. All are likely to have been defined as high-risk in any formal sex education received by the girls.

Demographic, accessibility and experiential measures The questionnaires also collected information about family background, access to contraceptives and sexual experiences. To examine the effect of socioeconomic status and social background, we include father's social class, coded non-manual (i.e. higher) vs manual (lower); living arrangements, coded with both birth parents vs other (single or step parent, etc.); housing tenure (privately owned vs social/rented); and educational attainment (achieved credit vs general/foundation Standard Grades; the examinations at the end of Scottish statutory education, with credit being the highest grade). Social class was derived from respondents' reports of their father's occupation and coded using 'Computer Assisted Standard Occupational Coding' software. ${ }^{15}$

The measures of access to contraceptives were having bought, or got free, condoms in the past year, and knowing where to access hormonal contraceptives. Experiential factors included negative (being under the influence of alcohol or drugs or pressurised by partner - asked for all three episodes of sexual intercourse) and positive (having talked to partner about protection or planned for/expected to have sex - asked for first and first with most recent partner episodes) sexual experiences. All factors had previously been found to be associated with contraceptive use. ${ }^{16}$

\section{Data analysis}

In this paper, we present results for three analyses: rates of contraceptive method use at each of the three episodes of sexual intercourse; contraceptive use and levels of pregnancy risk-taking behaviour across the three episodes according to contraceptive method used at first intercourse; and factors associated with greater pregnancy risk-taking behaviour at one or more of the three episodes.

The Pearson chi-squared $\left(\chi^{2}\right)$ test was used for bivariate comparisons. Logistic regression was used to produce unadjusted, and adjusted odds ratios, and to assess the significance of the risk factors for greater pregnancy risktaking behaviour. All variables significant at the bivariate level were included in the adjusted model. All factors were entered as categorical variables.

\section{Ethical approval}

The study was approved by Glasgow University's Ethics Committee for Non-Clinical Research Involving Human Subjects, and the relevant local authorities' education departments.

\section{Results}

\section{Contraceptive use}

Figure 1 shows the proportion reporting use of each contraceptive method at each episode of sexual intercourse. Overall, $83.4 \%, 82.8 \%$ and $82.1 \%$ of the 435 girls used some form of contraception at first, first with most recent partner, and most recent intercourse. Condom use throughout was the most common method at each episode but decreased from first to most recent $(51.7 \%, 44.6 \%$ and $34.9 \%)$. Contraceptive pill use $(4.8 \%, 14.3 \%$ and $20.9 \%)$ increased, while dual use of the pill and condom throughout was relatively stable $(12.2 \%, 12.0 \%$ and $13.8 \%)$. However, a quarter reported withdrawal, putting 


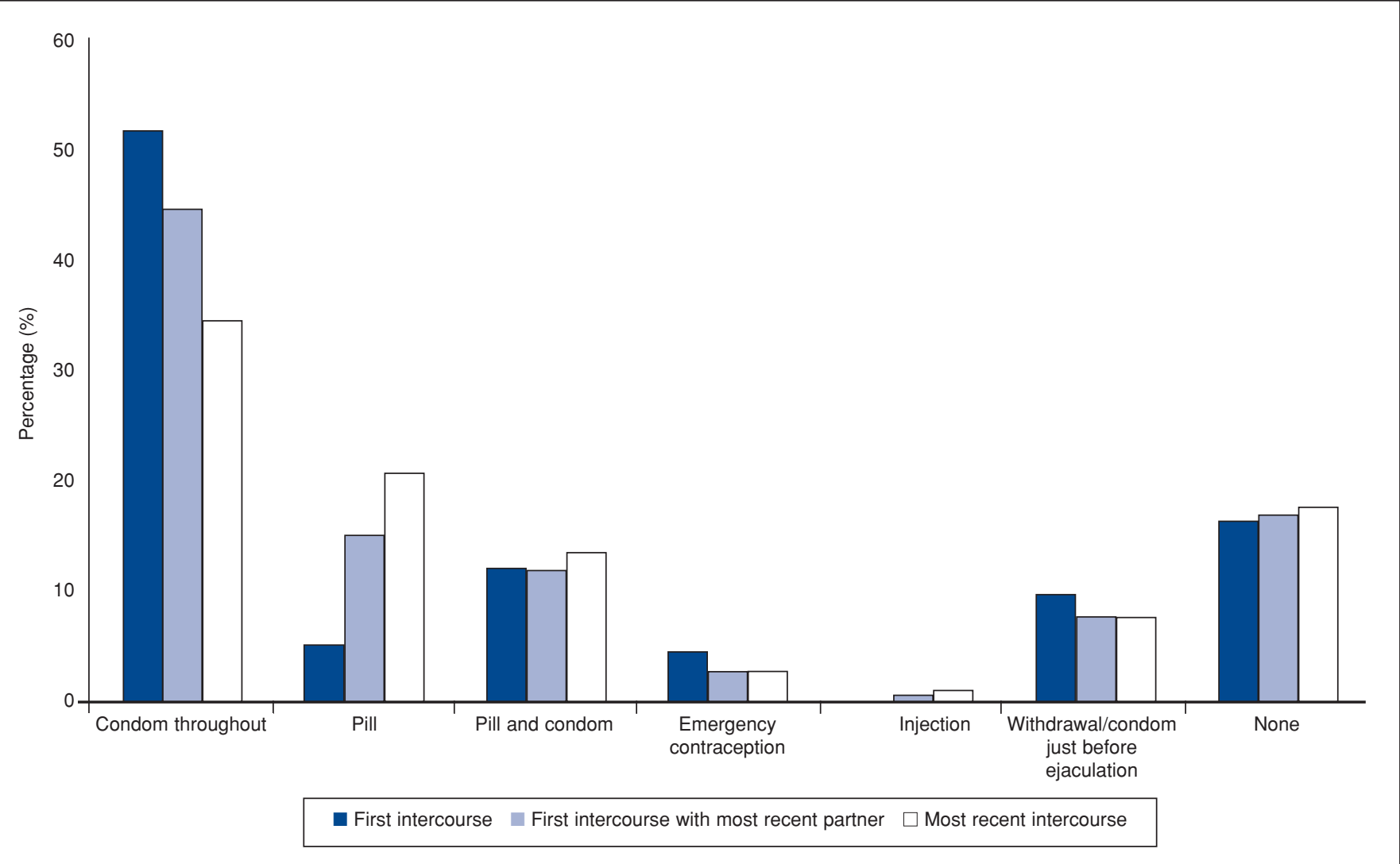

Figure 1 Contraceptive use at first, first with most recent partner, and most recent sexual intercourse among girls $(n=435)$ reporting on all three episodes by age 16 years

on a condom before ejaculation or non-use at first (26.5\%), first with most recent partner $(25.2 \%)$, and most recent intercourse $(25.9 \%)$.

\section{Contraceptive method use and pregnancy risk-taking behaviour}

Of the 435 girls, $320(73.6 \%)$ reported using a method, which suggested a lower level of pregnancy risk-taking behaviour at first intercourse (pill, condom throughout, EC, or a combination of these), while 115 (26.4\%) reported a method suggesting a higher level of pregnancy risk-taking behaviour (withdrawal, condom just before ejaculation, or non-use) (Table 1). Overall, $37.7 \%$ of the sample reported use of the same method at all three episodes (not shown in Table 1). This ranged from around $40 \%$ of those using the pill, condom throughout or a combination of the two, to around $15 \%$ of those reporting having used EC, withdrawal or putting on a condom before ejaculation. Of the 72 who

Table 1 Contraceptive methods and pregnancy risk-taking behaviour at first, first with most recent partner, and most recent sexual intercourse by contraceptive method at first intercourse $(n=435)$ : numbers and row percentages

\begin{tabular}{|c|c|c|c|c|c|c|c|c|}
\hline \multirow[t]{2}{*}{ Method used at first intercourse } & \multicolumn{2}{|c|}{$\begin{array}{l}\text { Lower pregnancy } \\
\text { risk }^{\mathrm{a}} \text { at all three } \\
\text { episodesc }\end{array}$} & \multicolumn{2}{|c|}{$\begin{array}{l}\text { Higher pregnancy } \\
\text { risk }^{b} \text { at one } \\
\text { episode }^{c}\end{array}$} & \multicolumn{2}{|c|}{$\begin{array}{l}\text { Higher pregnancy } \\
\text { risk }^{b} \text { at two } \\
\text { episodes }^{c}\end{array}$} & \multicolumn{2}{|c|}{$\begin{array}{l}\text { Higher pregnancy } \\
\text { riskb at all three } \\
\text { episodes }^{c}\end{array}$} \\
\hline & $n$ & (\%) & $n$ & (\%) & $n$ & (\%) & $n$ & (\%) \\
\hline \multicolumn{9}{|l|}{ Lower pregnancy risk $(n=320)$} \\
\hline Condom throughout $(n=225$ ) & 168 & $(74.7)$ & 32 & $(14.2)$ & 25 & $(11.1)$ & 0 & $(0.0)$ \\
\hline Pill $(n=21)$ & 17 & $(81.0)$ & 1 & $(4.8)$ & 3 & $(14.3)$ & 0 & $(0.0)$ \\
\hline Pill and condom $(n=53)$ & 47 & $(88.7)$ & 3 & $(5.7)$ & 3 & $(5.7)$ & 0 & $(0.0)$ \\
\hline Emergency contraception $(n=21)$ & 15 & $(71.4)$ & 4 & $(19.0)$ & 2 & $(9.5)$ & 0 & $(0.0)$ \\
\hline Subtotal & 247 & (77.2) & 40 & (12.5) & 33 & $(10.3)$ & 0 & (0.0) \\
\hline \multicolumn{9}{|l|}{ Higher pregnancy risk $(n=115)$} \\
\hline $\begin{array}{l}\text { Withdrawal/condom put on just before } \\
\text { ejaculation }(n=43)\end{array}$ & 0 & $(0.0)$ & 20 & $(46.5)$ & 8 & $(18.6)$ & 15 & (34.9) \\
\hline None $(n=72)$ & 0 & $(0.0)$ & 26 & (36.1) & 13 & (18.1) & 33 & $(45.8)$ \\
\hline Subtotal & 0 & $(0.0)$ & 46 & $(40.0)$ & 21 & (18.3) & 48 & $(41.7)$ \\
\hline Total $(n=435)$ & 247 & $(56.8)$ & 86 & (19.8) & 54 & (12.4) & 48 & $(11.0)$ \\
\hline
\end{tabular}

aLower pregnancy risk suggested by use of condoms, pill, injection, emergency contraception (EC) or a combination of these methods. bHigher pregnancy risk suggested by use of withdrawal, putting a condom on just before ejaculation or non-use of contraception.

cThe three episodes of sexual intercourse included in the analyses are at first, first with most recent partner, and most recent sexual intercourse. 
Table 2 Comparison of the characteristics of adolescent girls whose reported contraceptive method suggests lower and higher levels of pregnancy risk-taking behaviour: unadjusted and multivariate logistic regression $(n=435)$

\begin{tabular}{|c|c|c|c|c|c|c|c|c|c|c|}
\hline \multirow[t]{2}{*}{ Characteristics } & \multicolumn{2}{|c|}{$\begin{array}{l}\text { Lower pregnancy } \\
\text { risk at all three } \\
\text { episodes }(n=247)\end{array}$} & \multicolumn{2}{|c|}{$\begin{array}{l}\text { Higher pregnancy } \\
\text { risk at one or more } \\
\text { episodes }(n=188)\end{array}$} & \multicolumn{3}{|c|}{$\begin{array}{l}\text { Odds ratio for greater pregnancy } \\
\text { risk-taking behaviour at one } \\
\text { or more episodes (unadjusted) }\end{array}$} & \multicolumn{3}{|c|}{$\begin{array}{l}\text { Odds ratio for greater pregnancy } \\
\text { risk-taking behaviour at one } \\
\text { or more episodes }^{\text {(adjusted) }}{ }^{\mathrm{b}}\end{array}$} \\
\hline & $n$ & $(\%)$ & $n$ & (\%) & OR & $(95 \% \mathrm{Cl})$ & $p$ & OR & $(95 \% \mathrm{Cl})$ & $p$ \\
\hline \multicolumn{11}{|l|}{ Demographic factors } \\
\hline Non-manual & 86 & $(43.7)$ & 51 & (35.4) & 1 & & & - & & \\
\hline & 111 & (56.3) & 93 & (64.6) & 1.41 & $(0.91-2.20)$ & 0.13 & - & - & \\
\hline \multicolumn{11}{|l|}{ Living arrangements } \\
\hline $\begin{array}{l}\text { With single parent, } \\
\text { step-parent, etc. }\end{array}$ & 86 & $(34.8)$ & 75 & $(39.9)$ & 1.24 & $(0.84-1.84)$ & 0.28 & - & - & \\
\hline \multicolumn{11}{|l|}{ Housing tenure } \\
\hline Privately owned & 151 & $(68.0)$ & 92 & $(54.4)$ & 1 & & & 1 & & \\
\hline $\begin{array}{l}\text { Social (council) or rented } \\
\text { Educational attainment } \\
\text { (at age } 16 \text { years) }\end{array}$ & 71 & $(32.0)$ & 77 & $(45.6)$ & 1.78 & $(1.18-2.69)$ & 0.006 & 2.05 & $(1.21-3.48)$ & 0.007 \\
\hline $\begin{array}{l}\text { Credit level } \\
\text { Standard Gradesc }\end{array}$ & 177 & $(75.0)$ & 110 & $(63.2)$ & 1 & & & 1 & & \\
\hline $\begin{array}{l}\text { General/foundation level } \\
\text { Standard Grades }\end{array}$ & 59 & $(25.0)$ & 64 & $(36.8)$ & 1.75 & $(1.14-2.67)$ & 0.01 & 1.33 & $(0.79-2.26)$ & 0.29 \\
\hline \multicolumn{11}{|l|}{$\begin{array}{l}\text { Accessibility factors } \\
\text { Bought condoms in the }\end{array}$} \\
\hline Yes & 118 & $(48.6)$ & 64 & $(34.6)$ & 1 & & & 1 & & \\
\hline \multirow{2}{*}{\multicolumn{11}{|c|}{$\begin{array}{l}\text { Got condoms free from } \\
\text { a health service in the } \\
\text { last year }\end{array}$}} \\
\hline & & & & & & & & & & \\
\hline Yes & 151 & $(61.9)$ & 102 & $(54.5)$ & 1 & & & - & & \\
\hline No & 93 & (38.1) & 85 & (45.5) & 1.35 & $(0.92-1.99)$ & 0.13 & - & - & \\
\hline \multicolumn{11}{|l|}{$\begin{array}{l}\text { Know where can be } \\
\text { prescribed hormonal }\end{array}$} \\
\hline $\begin{array}{l}\text { Yes } \\
\text { No }\end{array}$ & $\begin{array}{r}228 \\
8\end{array}$ & $\begin{array}{r}(96.6) \\
(3.4)\end{array}$ & $\begin{array}{r}160 \\
19\end{array}$ & $\begin{array}{l}(89.4) \\
(10.6)\end{array}$ & $\begin{array}{l}1 \\
3.38\end{array}$ & $(1.45-7.92)$ & 0.005 & $\begin{array}{l}1 \\
2.92\end{array}$ & $(1.03-8.23)$ & 0.043 \\
\hline \multicolumn{11}{|l|}{$\begin{array}{l}\text { Experiential factors } \\
\text { Drunk or stoned at first }\end{array}$} \\
\hline \multicolumn{11}{|l|}{ sexual intercourse } \\
\hline Yes & 76 & $(31.1)$ & 83 & $(44.4)$ & 1.76 & $(1.19-2.62)$ & 0.005 & 1.37 & $(0.82-2.29)$ & 0.24 \\
\hline \multicolumn{11}{|l|}{$\begin{array}{l}\text { Pressurised by partner } \\
\text { at first sexual intercourse }\end{array}$} \\
\hline No & 188 & $(77.7)$ & 118 & $(65.2)$ & 1 & & & 1 & & \\
\hline \multirow{2}{*}{\multicolumn{11}{|c|}{$\begin{array}{l}\text { Talked to partner about } \\
\text { protection before first } \\
\text { sexual intercourse }\end{array}$}} \\
\hline & & & & & & & & & & \\
\hline Yes & 155 & $(72.8)$ & 46 & (28.9) & 1 & & & 1 & & \\
\hline No & 58 & $(27.2)$ & 113 & $(71.1)$ & 6.57 & $(4.16-10.36)$ & $<0.001$ & 3.52 & $(2.06-6.02)$ & $<0.001$ \\
\hline \multicolumn{11}{|l|}{$\begin{array}{l}\text { Planned first sexual } \\
\text { intercourse }\end{array}$} \\
\hline Planned or expected it & 135 & $(62.2)$ & 58 & $(34.5)$ & 1 & & & 1 & & \\
\hline $\begin{array}{l}\text { Unexpected or spur } \\
\text { of the moment }\end{array}$ & 82 & $(37.8)$ & 110 & $(65.5)$ & 3.12 & $(2.05-4.75)$ & $<0.001$ & 2.20 & $(1.31-3.70)$ & 0.003 \\
\hline \multicolumn{11}{|l|}{$\begin{array}{l}\text { Drunk or stoned at first } \\
\text { sexual intercourse with }\end{array}$} \\
\hline $\begin{array}{l}\text { most recent partner } \\
\text { No }\end{array}$ & 193 & $(79.1)$ & 122 & $(65.6)$ & 1 & & & 1 & & \\
\hline Yes & 51 & (20.9) & 64 & $(34.4)$ & 1.99 & $(1.29-3.06)$ & 0.002 & 1.33 & $(0.75-2.34)$ & 0.33 \\
\hline \multicolumn{11}{|l|}{$\begin{array}{l}\text { Pressurised by partner at } \\
\text { first sexual intercourse with } \\
\text { most recent partner }\end{array}$} \\
\hline No & 224 & $(91.4)$ & 164 & (88.6) & 1 & & & _- & & \\
\hline Yes & 21 & (8.6) & 21 & (11.4) & 1.37 & $(0.72-2.58)$ & 0.34 & - & - & \\
\hline \multicolumn{11}{|l|}{$\begin{array}{l}\text { Talked to partner about } \\
\text { protection before first sexual } \\
\text { intercourse with most } \\
\text { recent partner }\end{array}$} \\
\hline Yes & 161 & (73.5) & 56 & (34.6) & 1 & & & 1 & & \\
\hline No & 58 & (26.5) & 106 & $(65.4)$ & 5.25 & (3.38-8.17) & $<0.001$ & 3.61 & $(2.09-6.23)$ & $<0.001$ \\
\hline $\begin{array}{l}\text { Planned first sexual } \\
\text { intercourse with most recent } \\
\text { partner }\end{array}$ & & & & & & & & & & \\
\hline Planned or expected it & 137 & $(60.4)$ & 84 & $(46.4)$ & 1 & & & 1 & & \\
\hline $\begin{array}{l}\text { to happen soon } \\
\text { Unexpected or spur of } \\
\text { the moment }\end{array}$ & 90 & $(39.6)$ & 97 & $(53.6)$ & 1.76 & $(1.18-2.61)$ & 0.005 & 1.20 & $(0.72-2.01)$ & 0.48 \\
\hline Drunk or stoned at most & & & & & & & & & & \\
\hline recent sexual intercourse & & & & & & & & & & \\
\hline $\begin{array}{l}\text { No } \\
\text { Yes }\end{array}$ & 196 & $(80.0)$ & 137 & $(73.3)$ & 1 & (1) & 010 & - & & \\
\hline $\begin{array}{l}\text { Yes } \\
\text { Pressurised by partner at } \\
\text { most recent sexual }\end{array}$ & 49 & (20.0) & 50 & $(26.7)$ & 1.46 & $(0.93-2.29)$ & 0.10 & - & - & \\
\hline $\begin{array}{l}\text { intercourse } \\
\text { No }\end{array}$ & 217 & $(90.0)$ & 164 & $(91.6)$ & 1 & & & _- & & \\
\hline Yes & 24 & $(10.0)$ & 15 & (8.4) & 0.83 & $(0.42-1.63)$ & 0.58 & - & - & \\
\hline
\end{tabular}

aThe three episodes of sexual intercourse included in the analyses are at first, first with most recent partner, and most recent sexual intercourse. bAll variables significant at the bivariate level were included in the adjusted model. cStandard Grades are the examinations at the end of Scottish statutory education, with credit being the highest level. $\mathrm{Cl}$, confidence interval; OR, odds ratio. 
reported non-use at first intercourse, 28 (38.9\% of those reporting this at first intercourse; $6.4 \%$ of the overall sample) reported non-use at all three episodes.

Table 1 shows that more than half $(56.8 \%)$ reported using methods that suggested lower pregnancy risk-taking behaviour (abbreviated to 'lower pregnancy risk') at all three episodes, $19.8 \%$ reported higher pregnancy risktaking behaviour ('higher pregnancy risk') at one episode, $12.4 \%$ at two, and $11.0 \%$ at all three. Most $(n=247$, $77.2 \%$ ) of those who reported a 'lower pregnancy risk' method at first intercourse did so at all of the three episodes (range 71.4-88.7\%, highest among those reporting combined use of condoms and the pill at first intercourse). However, $40(12.5 \%)$ reported using a 'higher pregnancy risk' method at one subsequent episode, and $33(10.3 \%)$ at both. Among the 43 reporting withdrawal or putting on a condom just before ejaculation at first intercourse, over one-third (34.9\%) reported use of 'higher pregnancy risk' methods at all three episodes. Use of 'higher pregnancy risk' methods at all three episodes was even greater (45.8\%) among the 72 reporting non-use of contraception at first intercourse. However, $46(40.0 \%)$ of the 115 who reported a method suggesting 'higher pregnancy risk' at first intercourse did not do so at either of the next episodes.

The self-reported pregnancy experience of each group was compared (note $n=353$; this question was excluded by one education authority). Girls categorised as being at 'lower pregnancy risk' at all three episodes were significantly less likely to report having experienced a pregnancy by age 16 years than the rest of this sample: $8.9 \%(17 / 192)$ compared with $22.5 \%(16 / 71)$ of those at 'higher pregnancy risk' at one episode $\left(\chi^{2}=8.84\right.$, $p=0.003), 24.4 \%(11 / 45)$ of those higher at two $\left(\chi^{2}=8.51\right.$, $p=0.004)$, and $20.0 \%(9 / 45)$ of those higher at all three $\left(\chi^{2}=4.64, p=0.031\right)$. There was no significant difference in the self-reported pregnancy experience of the three latter groups $\left(\chi^{2}=0.26, p=0.88\right)$.

\section{Factors associated with pregnancy risk-taking behaviour}

Table 2 compares the characteristics of the girls who did $(n=188)$ and did not $(n=247)$ report use of a 'higher pregnancy risk' method at any of the three episodes of sexual intercourse. The three 'higher pregnancy risk' groups were combined for these analyses, given the comparable self-reported pregnancy experiences shown above. Those who had used a 'higher pregnancy risk' method at some point were significantly more likely to live in social or rented accommodation and to have lower grades at the end of statutory education. Just over one-third had bought condoms, compared with almost half those reporting use of a 'lower pregnancy risk' method; $10.6 \%$ reported not knowing where they could be prescribed hormonal contraceptives, compared with $3.4 \%$. The 'higher pregnancy risk' group were significantly more likely to report having been under the influence of drink or drugs at two episodes of sexual intercourse (first and first with most recent partner), pressure at first sex, and that first ever and first with most recent partner sex were unexpected or happened on the spur of the moment. They were also significantly less likely to have talked to their partner (both first and most recent) about protection prior to sex.

When all of the significant factors were entered into the adjusted logistic regression model, the following remained significant: living in social or rented accommodation, not knowing where to get prescription hormonal contraceptives, reporting first sex was pressurised, unexpected or spur of the moment, and not having talked to partner (both first and most recent) about protection prior to sex. These mutually adjusted analyses indicate the independent effects of each factor (Table 2). The Hosmer and Lemeshow Goodness of Fit Test was non-significant $(p=0.121)$, indicating that the model was a good fit to the data. To check for the effects of collinearity, correlations between the predictors were examined. For variables with moderate or high correlations, separate models were fitted for each of the correlated variables and compared with the final model. No substantively important differences were observed. Sensitivity analysis, in the form of a backward stepwise model, was conducted to check the result of the original model; in the final model, the variables not significant in the original adjusted logistic regression model were removed and having been pressurised by partner at first sex increased in significance $(p=0.034)$.

\section{Discussion}

Before discussing these results, some limitations should be considered. First, the SHARE questionnaire only asked about three episodes of sexual intercourse, and respondents were not asked why they used particular contraceptive methods at each episode. First sexual intercourse and first with most recent partner are particular events, which could be different from others. It is possible that further differences in contraceptive use and pregnancy risk-taking behaviour would have been revealed if the questionnaire had explored what happened in between these events. However, reporting the same method at each event is indicative of consistency.

Second, the questionnaire contained a predetermined list of contraceptive methods. Although all the main methods were listed, and respondents could select more than one answer and add others, it is possible that some, particularly the injection or implant, were under-reported. However, use of these methods remains low in the UK (only 7\% of 16-19-year-old contraceptive users report use ${ }^{17}$ ), so it could be surmised that use would be particularly low among the group studied here.

Third, the categorisation of pregnancy risk-taking behaviour does not account for the girls' own experiences of use. Assessment of 'user' efficacy was not possible from the data collected. The pill and condoms are effective contraceptive methods only when used correctly..$^{9} \mathrm{EC}$ was also included in the 'lower pregnancy risk' group, even though it was probably required as a result of contraceptive non-use or failure. However, in a related qualitative study, we have shown that EC was predominantly viewed by young women as a 'back-up' method,12 and we would argue that its use suggests the girls considered themselves at risk of pregnancy and addressed this, which supports its inclusion in this group. Our classification of pregnancy risk was validated by the significantly lower pregnancy rates among those categorised as displaying lower levels of pregnancy risk-taking behaviour at all three episodes of intercourse.

Notwithstanding these limitations, this study's focus on those who have had a relatively early sexual debut and more than one sexual partner by age 16 years provides information on a particularly vulnerable group in the sexual health field. Examining contraceptive use and non-use among these girls is important for ascertaining the nature of vulnerability in this area and addressing unwanted sexual outcomes through targeted interventions.

Consistent, correct use of an effective contraceptive method offers the best protection against pregnancy. ${ }^{9}$ Just over half this sample had consistently used contraceptive methods traditionally advocated for pregnancy prevention in formal sex education and suggestive of a lower level of 
pregnancy risk-taking behaviour. Over one-third reported use of the same method at all three episodes of intercourse examined, and most who changed method did so to a method traditionally considered effective. ${ }^{9}$ However, just under half reported method use suggestive of greater pregnancy risk-taking behaviour at some point; one in ten did so at all three episodes of sexual intercourse. Crucially, the positive message from these analyses is that most of the girls used an effective method of contraception at any given episode of intercourse for which we have data. Less positively, around one in four were using no, or an ineffective, method, which suggested greater pregnancy risk-taking behaviour, at any of these same episodes. The one in ten with consistently greater pregnancy risk-taking behaviour are of particular concern.

The next step in considering what can be done to modify behaviour in these cases is to better understand why contraception is not being used. Given the similar levels of pregnancy experience reported by the girls who displayed greater pregnancy risk-taking behaviour at one, two and all three episodes of intercourse, these were combined in analyses which demonstrated that this behaviour was associated with social and educational disadvantage. This supports findings elsewhere. ${ }^{18,19}$ In disadvantaged communities where teenage motherhood is common, pregnancy could be a rational choice through lack of desirable, or achievable, (educational or career-orientated) alternatives. ${ }^{20-23}$ Challenging such negative norms is a recognised policy goal, but one that remains to be achieved.

Greater pregnancy risk-taking behaviour was also associated with lower levels of knowledge and access to contraceptives and negative experiences of sexual intercourse. It is often those with less confidence, and who are unwilling to plan or talk about contraception, who are less likely to use contraception or access sexual health services. ${ }^{19,24,25}$ Again, increasing access to, and ability to use contraceptives are important components of efforts to reduce teenage pregnancy. Perhaps more needs to be done to identify the girls who are consistently failing to use contraception and understand what it might be about particular episodes of sexual intercourse that result in ineffective or non-use of contraception.

This is perhaps the greatest challenge for policymakers and practitioners. Identifying, within the community, those girls who are putting themselves at repeated risk of pregnancy is essential to target interventions. We also need to know more about varying contexts which mean that girls who are capable of using effective contraception on one occasion may not do so on another. More in-depth work, using qualitative methods, is needed to elucidate these issues. Only then can tailored and targeted interventions be developed to ensure that the needs of the most vulnerable are met within broader initiatives to reduce teenage pregnancy rates.

\section{Statements on funding and competing interests}

Funding This study was funded by the UK Medical Research Council as part of the Sexual and Reproductive Health Programme (WBS U.1300.00.005) at the Social and Public Health Sciences Unit.

Competing interests None identified.

\section{Acknowledgements}

The authors would like to thank the young people who participated in the study and their teachers who facilitated this; the project team, in particular Marion Henderson, the survey manager, and Daniel Wight, the principal investigator; and Geoff Der for statistical advice.
References

1 United Nations Children's Fund (UNICEF). A League Table of Teenage Births in Rich Nations (Innocenti Report Card No. 3). Florence, Italy: UNICEF Innocenti Research Centre, 2001.

2 Sexually Transmitted Infection Epidemiology Advisory Group. Scotland's Sexual Health Information, 2008. Edinburgh, UK: Health Protection Scotland and Information Services Division, 2008.

3 Office for National Statistics, Teenage Pregnancy Unit. Teenage Conception Statistics for England, 1998-2007. London, UK: Office for National Statistics, 2009.

4 Wellings K, Nanchahal K, Macdowall W, McManus S, Erens B, Mercer $\mathrm{CH}$, et al. Sexual behaviour in Britain: early heterosexual experience. Lancet 2001; 358: 1843-1850.

5 Scottish Executive. Respect and Responsibility: Strategy and Action Plan for Improving Sexual Health. Edinburgh, UK: Scottish Executive, 2005.

6 Department for Education and Skills. Teenage Pregnancy: Accelerating the Strategy to 2010. London, UK: Department for Education and Skills, 2006.

7 Wight D, Raab GM, Henderson M, Abraham C, Buston K, Hart $\mathrm{G}$, et al. Limits of teacher delivered sex education: interim behavioural outcomes from randomised trial. BMJ 2002; 324: 1430 [erratum appears in BMJ 2002; 325: 435].

8 Henderson M, Wight D, Raab G, Abraham C, Parkes A, Scott $S$, et al. The impact of a theoretically based sex education programme (SHARE) delivered by teachers on NHS registered conceptions and terminations: final results of cluster randomised trial. BMJ 2007; 334: 133-135.

9 Kubba A, Guillebaud J, Anderson RA, MacGregor EA. Contraception. Lancet 2000; 356: 1913-1919.

10 Jones RK, Fennell J, Higgins JA, Blanchard K. Better than nothing or savvy risk-reduction practice? The importance of withdrawal. Contraception 2009; 79: 407-410.

11 Pudney J, Oneta M, Mayer K, Seage G, Anderson D. Preejaculatory fluid as potential vector for sexual transmission of HIV-1. Lancet 1992; 340: 1470.

12 Williamson LM, Buston K, Sweeting H. Young women's perceptions of pregnancy risk and use of emergency contraception: findings from a qualitative study. Contraception 2009; 79: 310-315.

13 Ziebland S, Wyke S, Seaman P, Fairhurst K, Walker J, Glasier A. What happened when Scottish women were given advance supplies of emergency contraception? A survey and qualitative study of women's views and experiences. Soc Sci Med 2005; 60: 1767-1779.

14 Simonds W, Ellertson C. Emergency contraception and morality: reflections of health care workers and clients. Soc Sci Med 2004; 58: 1285-1297.

15 Elias P, Halstead K, Prandy K. Computer Assisted Standard Occupational Coding. London, UK: HMSO Books, 1993.

16 Williamson LM. Contraceptive careers: young women's choices, influences and risks. PhD thesis, University of Glasgow, Glasgow, UK, 2007. E-thesis available at http://theses.gla.ac.uk/164/ [Accessed 26 August 2009].

17 Lader D. Contraception and Sexual Health 2006/07. London, UK: Office for National Statistics, 2007.

18 Bonell CP, Strange VJ, Stephenson JM, Oakley AR, Copas AJ, Forrest SP, et al. Effect of social exclusion on the risk of teenage pregnancy: development of hypotheses using baseline data from a randomised trial of sex education. $J$ Epidemiol Community Health 2003; 57: 871-876.

19 Health Education Authority. Reducing the Rate of Teenage Conceptions - Young People's Experiences of Relationships, Sex and Early Parenthood: Qualitative Research. London, UK: Health Education Authority, 1999.

20 Arai L. Low expectations, sexual attitudes and knowledge: explaining teenage pregnancy and fertility in English communities. Insights from qualitative research. Sociol Rev 2003; 51: 199-217.

21 Coleman L, Cater S. 'Planned' teenage pregnancy: perspectives of young women from disadvantaged backgrounds in England. J Youth Stud 2006; 9: 593-614.

22 Martyn KK, Hutchinson SA. Low-income African American adolescents who avoid pregnancy: tough girls who rewrite negative scripts. Qual Health Res 2001; 11: 238-256.

23 Thomson R. Dream on: the logic of sexual practice. $J$ Youth Stud 2000; 3: 407-427.

24 Parkes A, Wight D, Henderson M. Teenagers' use of sexual health services: perceived need, knowledge and ability to access. J Fam Plann Reprod Health Care 2004; 30: 217-224.

25 Stone N, Ingham R. When and why do young people in the United Kingdom first use sexual health services? Perspect Sex Reprod Health 2003; 35: 114-120. 